\title{
Comparative effectiveness and costs of generic and brand-name gabapentin and venlafaxine in patients with neuropathic pain or generalized anxiety disorder in Spain
}

\author{
This article was published in the following Dove Press journal: \\ ClinicoEconomics and Outcomes Research \\ 4 June 2015 \\ Number of times this article has been viewed
}

\author{
Antoni Sicras-Mainar' \\ Javier Rejas-Gutiérrez ${ }^{2}$ \\ Ruth Navarro-Artieda ${ }^{3}$ \\ 'Planning Directorate, Badalona \\ Serveis Assistencials SA, Badalona, \\ Barcelona, Spain; ${ }^{2}$ Department \\ of Health Economics and \\ Outcomes Research, Pfizer SLU, \\ Alcobendas, Madrid, Spain; ${ }^{3}$ Medical \\ Documentation, Hospital Germans \\ Trias i Pujol, Badalona, Barcelona, \\ Spain
}

Objective: To explore adherence/persistence with generic gabapentin/venlafaxine versus brand-name gabapentin/venlafaxine $\left(\right.$ Neurontin $^{\circledR} /$ Vandral $^{\mathbb{}}$ ) in peripheral neuropathic pain $(\mathrm{pNP})$ or generalized anxiety disorder (GAD), respectively, and whether it is translated into different costs and patient outcomes in routine medical practice.

Methods: A retrospective, new-user cohort study was designed. Electronic medical records (EMR) of patients included in the health plan of Badalona Serveis Assistencials SA, Barcelona, Spain were exhaustively extracted for analysis. Participants were beneficiaries aged $18+$ years, followed between 2008 and 2012, with a pNP/GAD International Classification of Diseases, Ninth Revision, Clinical Modification (ICD-9-CM) code, who initiated treatment with generic or brand-name gabapentin or venlafaxine. Assessments included 1-year treatment persistence and adherence (medication possession ratio), health care costs, and reduction in severity of pain and anxiety symptoms.

Results: A total of 2,210 EMR were analyzed; 1,369 on gabapentin (brand 400; generic 969) and 841 on venlafaxine (brand 370 and generic 471). Brand-name gabapentin and venlafaxine were both significantly associated with longer persistence than generic: 7.3 versus 6.3 months, $P<0.001$; and 8.8 versus 8.1 months, $P<0.05$, respectively. Brand-name was associated with higher adherence: $86.5 \%$ versus $81.3 \%, P<0.001$; and $82.1 \%$ versus $79.0 \%, P<0.05$, respectively. Adjusted average costs were higher with generic compared with brand: $€ 1,277$ versus $€ 1,057$ (difference of $€ 220$ per patient; $P<0.001$ ) for gabapentin; and $€ 1,110$ versus $€ 928$ (difference of $€ 182$ per patient; $P=0.020$ ) for venlafaxine, both because of more use of medical visits and concomitant medication. Compared with generic, brand-name was associated with higher reduction in pain $(7.8 \% ; P<0.001)$ and anxiety $(13.2 \% ; P<0.001)$.

Conclusion: Patients initiating brand-name gabapentin or venlafaxine were more likely to adhere and persist on treatment of pNP or GAD, have lower health care costs, and show further reduction of pain and anxiety symptoms than with generic drugs in routine medical practice.

Keywords: brand medicinal products, generic medicinal products, adherence, persistence, use of resources, costs, outcomes

\section{Introduction}

Peripheral neuropathic pain (pNP), defined as pain initiated or caused by a primary lesion or nervous system dysfunction, is a common symptom. ${ }^{1,2}$ The prevalence is estimated at $1 \%-8 \%$ in the adult population and represents around $40 \%$ of cases of chronic pain at primary care office visits. ${ }^{3,4}$ Generalized anxiety disorder (GAD) is characterized by having symptoms of anxiety most days for at least several weeks, ${ }^{5,6}$
Correspondence: Antoni Sicras-Mainar Assistencials SA, Calle Gaietà Soler, 6-8 entlo., 089II, Badalona,

Barcelona, Spain

Tel +3493 5072684

Fax +3493507 2684

Email asicras@bsa.cat 
and it is the most common type of anxiety disorder seen in primary care, ${ }^{7}$ with a prevalence of around $2 \%-5 \%$ in the general population, and also accounting for an important workload at the physician office. ${ }^{6,8}$ These two medical conditions may have different pathophysiological mechanisms, but the reason of including both relates to their high prevalence in primary care, and related workload. Moreover, the chronic nature of the symptoms and the disability they often cause can produce considerable direct costs for health services and indirect costs resulting from absenteeism. ${ }^{9,10}$ These circumstances affect all aspects of patient lives: family, social, and work. As such, many patients are not properly diagnosed, receive inadequate drug treatment, or are on lower doses than they should be. ${ }^{11,12}$ For this reason, both conditions may be considered of relevance and pertinent to both clinicians and payers.

Drug therapy is one of the essential bases of treatment. It is known that generic medicinal products have the same efficacy, safety, and quality as the original brand-name, and are bioequivalent. ${ }^{13,14}$ Motivation, the physician's awareness, and health intervention policies on generics are some of the factors influencing their use. ${ }^{14}$ In general, patients are demanding better health care and want cost-effectiveness, ${ }^{13}$ and this is a key component of the negotiation between payers, managers, and health professionals. In Spain, current policy regarding the restriction of the price of brand drugs compared with generics is no longer such a strong argument for requiring their use since they have, actually, the same financed price. Reviewing the available literature, some authors have found no pharmacological arguments against prescribing these products. ${ }^{15,16}$ Others, however, disagree (brand vs generic) in the context of routine clinical practice for a number of reasons, one being treatment adherence, which can often lead to decreased effectiveness (confusing for patients, lack of therapeutic control, poor health outcomes) and a potential increase in associated health care costs. ${ }^{17-20}$ Additionally, there is little evidence available on the relationship between these variables in routine clinical practice, and none on the impact on use of health care resources and their respective costs.

Thus, it is worthy to explore such controversy in health conditions that are relevant and pertinent to both clinicians and payers, and the health problems selected here seem to be aligned with such purpose and may be useful to illustrate the matter of this study. Our objective was, then, to estimate the treatment adherence and persistence in patients who initiated the therapy of either pNP or GAD with generic gabapentin/venlafaxine versus brand-name gabapentin/ venlafaxine (Neurontin ${ }^{\circledR} /$ Vandral $^{\circledR}$ ), and to compare whether it is translated into different costs and patient outcomes for pain and anxiety symptoms, in routine clinical practice in Spain.

\section{Patients and methods Study design and population}

This was an observational, multicenter, retrospective study conducted by analyzing the electronic medical records (EMR) of patients included in the health plan of Badalona Serveis Assistencials (BSA) SA, a health provider in Badalona (Barcelona), Spain. Records from patients included in the study were followed at primary care level in any of the seven primary care (PC) health centers owned by BSA. Patients seeking care and who initiated a new treatment with gabapentin (Neurontin ${ }^{\circledR}$ or generic) or venlafaxine (Vandral ${ }^{\circledR}$ or generic) within years 2008-2012 (period of recruitment, index date) were included in the study. Patients had to fulfill the following inclusion criteria: age 18+ years; followed actively in BSA for at least 12 months before the start of the study; be in the refill prescription program for long-term medication (with record of the daily dose, time interval, and duration of each treatment administered; $\geq 2$ prescriptions during the followup period); guarantee of regular monitoring of patients during the study period ( $\geq 2$ health records in the computer system); and diagnosed with pNP or GAD. Subjects transferred to other centers, displaced or outside area, patients permanently institutionalized, those who changed treatment (brand vs generic) in either direction, and patients who were prescribed the two active substances concomitantly (gabapentin and venlafaxine) were excluded from the analysis.

\section{Study groups and calculation of sample size}

There were two study groups: 1) patients initiating treatment with gabapentin for pNP for the first time; and 2) patients initiating treatment with venlafaxine for GAD for the first time. Each group had two subgroups: brand-name and generic. Generic prescription could be from different drug makers during the course of the study, even in the same patient, as it happens in routine medical practice in Spain. Patients were followed-up for 12 months after starting the medication. The calculation of sample size was established by finding a minimum difference of $€ 60$ (SD, 240) between brand and generic gabapentin and $€ 40$ (SD, 160) between brand and generic venlafaxine. With an error $\alpha<0.05$ and an error $\beta<0.1$, these differences would enable detection of even the smallest differences according to Cohen's $d$-statistic with a minimal effect size of 0.25 . With these parameters, 
the study needed at least 340 sets of medical records in each of the four study groups. However, all available records that met the selection criteria in the study period from the start date were obtained (exhaustive sampling).

\section{Diagnosis and scales}

The records of patients with pNP or GAD were obtained using the International Classification of Primary Care (ICPC-2), ${ }^{21}$ codes N92-N94 or P74, and/or the International Classification of Diseases (ninth edition) Clinical Modification (ICD9th-CM, codes 350.1, 352.1, 352.9, 353.1, 352.2, 353.3, 353.6, 353.8, 354.0, 355.1, 355.5, 357.2, 357.4, 357.8, 357.9, 053.12 , and 300.02 ). The criteria were always at discretion of the physician.

To estimate clinical effectiveness, we used the information recorded in the medical records on the Numeric Rating Scale (NRS) for pain, ${ }^{22}$ for assessing the intensity of $\mathrm{pNP}$ in a range from 0 (no pain) to 10 (worst pain imaginable), and the Hamilton Anxiety Rating Scale (HARS, HAM-A) for GAD, ${ }^{23}$ with 14 items ranging from 0 to 56 points ( $<7$ points signifies no anxiety or in remission). The initial and final values were obtained (from first and last records available, respectively). Sociodemographic and comorbidity variables were also collected which included age (continuous and by range), time since diagnosis, and sex, in addition to previous medical history obtained using ICPC-2. ${ }^{21}$ The following were used as general comorbidity summary variables: 1) the Charlson Comorbidity Index as an estimate of the patient's severity; ${ }^{24}$ and 2 ) the individual case-mix index, obtained from the Adjusted Clinical Groups (ACG), a system for grouping patients according to resource consumption (isoresource groups). ${ }^{25}$ The ACG provides resource utilization bands (RUB) so that each patient, depending on his/her overall morbidity, is grouped into one of five mutually exclusive categories: 1) healthy users or very low morbidity, 2) low morbidity, 3) moderate morbidity, 4) high morbidity, and 5) very high morbidity.

\section{Medication, treatment adherence, and persistence}

Medications prescribed for the treatment of $\mathrm{pNP}$ and GAD were classified according to the Anatomical Therapeutic Chemical (ATC) classification system. ${ }^{26}$ The information was obtained from the pharmacological dispensing records for drugs issued by the "CatSalut" (Catalan Health Service) application. The choice of drug for a particular patient was at the discretion of the doctor (clinical practice). Information was also obtained on treatment duration and the number of treatments given (6 months) prior to starting gabapentin or venlafaxine. The "adherence rate" was defined according to the International Society for Pharmacoeconomics and Outcomes Research criteria and calculated from the medication utilization/medication possession ratio (MPR). ${ }^{27}$ This was assessed from the first to the last prescription and represents the number of days of medication supplied divided by the number of days on treatment (counted from the index date to the last possible day with available medication). ${ }^{28}$ "Persistence", measured in months, was defined as the elapsed time between the index date (which corresponds to the first prescription of study drug) and the ending date (which corresponds to the date of last refill plus the number of pills/tablets prescribed) without discontinuing the initial treatment or without changing to another medication at least 30 days after the initial prescription. Treatment persistence was also assessed as the percentage of patients taking the initial treatment $3,6,9$, and 12 months since the index date.

\section{Use of resources and cost analysis}

"Health care costs" were considered to be those relating to health care activity (medical visits, days of hospitalization, hospital emergencies, and diagnostic or therapeutic referral requests) performed by health care professionals, and "non-health care costs" (indirect costs) were those relating to loss of labor productivity (days of temporary sick leave), all of them related with the heath conditions studied here. Out-of-pocket costs were not collected in the study. The cost system design was defined considering the characteristics of the health provider and the degree of development of the available information systems. The product unit that served as the basis for the final calculation (during the study period) was the treated patient and the cost was expressed as average cost per patient (average cost/unit). The study's different concepts and their economic values are shown in Table 1 (corresponding to year 2013). Different fees were obtained from analytical accounting at the sites, except medication and days off work. Prescriptions were quantified by retail price per pack at the time of prescribing. Days off work or productivity losses were considered to be non-health care costs (indirect). The cost was quantified according to minimum wage. ${ }^{29}$

As happens in any retrospective study using existing recorded data, we dealt with the risk of not recording information properly or missing data. This problem was minimized, thanks to regular quality control of the database by the health provider, continuous training of physicians, and specific validation of the informatics system. 
Table I Details of the unit costs and lost labor productivity (2013)

\begin{tabular}{ll}
\hline Health care and non-health care resources & Unit costs $(\boldsymbol{\epsilon})$ \\
\hline Doctors' visits & \\
Primary care doctors visit & 23.7 \\
Emergency room visits & 119.9 \\
Hospitalization (I day) & 327.3 \\
Specialist doctors visit & 68.9 \\
Day hospital sessions & 184.8 \\
Investigations & \\
Laboratory tests & 22.7 \\
Conventional radiology & 18.9 \\
Diagnostic/therapeutic tests & 37.9 \\
Pharmaceutical prescription & Public selling price \\
Labor productivity - indirect costs & \\
Cost per day not worked & 79.5 \\
\hline
\end{tabular}

Notes: Source of health care resources: analytical accounting of Badalona Serveis Assistencials and by Instituto Nacional de Estadística (INE). ${ }^{29}$ Values are expressed in euros $(€)$.

\section{Ethics}

The study followed the basic ethical principles contained in the Declaration of Helsinki for studies in the human being. The study protocol was first classified as a PostAuthorization Study - Other Designs (PAS-OD) by the Spanish Agency for Medicines and Medical Devices and, secondly, was reviewed and approved by the Independent Ethics Committee of Hospital Germans Trias i Pujol de Badalona, Barcelona. Data from subjects underwent a process of dissociation to preserve patient anonymity as set out in the Spanish Personal Data Protection Act 15/1999 of 13 December.

\section{Statistical analysis}

Data were first carefully examined by exploratory analysis and specifically prepared, noting their frequency distribution and checking for possible data input or coding errors. A descriptive univariate statistical analysis was carried out after verifying normal distribution with the KolmogorovSmirnov test. The homogeneity of the data analyzed was checked according to geographical area of the participating sites. The analysis of geographical homogeneity showed no differences which were either statistically significant or of a relevant magnitude.

Persistence with the treatments being evaluated was initially analyzed descriptively, calculating the proportion of patients who remained on treatment at 3, 6, 9, and 12 months after the index date. Also, cumulative survival was estimated in the study of each cohort using the Kaplan-Meier method to calculate the unadjusted cumulative proportion of persistence at different times from the start of treatment. Statistical significance was analyzed with the Mantel-Cox (log-rank) test.
The analysis of resource utilization and associated costs included an initial bivariate analysis without controlling for potential confounding variables in which robust analysis of variance (ANOVA) (Welch and Brown-Forsythe test with subsequent pairwise comparisons using the Games-Howell test) and chi-tests were used according to data distribution. The use of resources and their associated costs were compared as recommended by Thompson and Barber using a general linear model (analysis of covariance [ANCOVA]) adjusted for the covariates sex, age, overall comorbidity (RUB, Charlson index), illness duration, the MPR, and treatment persistence. ${ }^{30}$ Pairwise comparisons were adjusted to the procedure to estimate marginal means using the Bonferroni correction to estimate the $P$-value of statistical significance. Data were presented as adjusted mean differences between treatments with their respective $95 \%$ confidence interval calculated with re-sampling techniques (bootstrapping) corrected for bias, given the non-normal distributions of the resource utilization and cost variables.

Pain intensity and severity of anxiety symptoms were analyzed after performing a single imputation of missing values using a general linear model (ANCOVA) for absolute and relative variation between start and discontinuation of treatment of the pain and anxiety scores, respectively, and using a logistic regression model for the proportion of patients who were responders or in remission in terms of anxiety symptoms (score $<7$ points on the HAM-A scale), or had no pain/mild pain (score $<4$ on the NRS). The covariates used in the ANCOVA and logistic regression model were age, sex, and the score on the corresponding scale at the start of treatment. Missing values in the NRS were observed in $9.7 \%$ of patients receiving gabapentin, with no significant difference between brand (8.5\%) and generic (10.2\%), $P=0.382$. On the HAM-A scale, missing values were observed in $22.2 \%$ of patients receiving venlafaxine, also with no significant difference between brand (20.3\%) and generic (23.8\%), $P=0.258$. Imputation method was WOCF (worst available observation carried forward), which in this case was the score observed at the start-of-treatment visit. For both scales, we compared the scores at the first and final visits, absolute (points) and relative ( $\%)$ variation of pain intensity and anxiety severity between visits, proportion of responders (reduction $\geq 50 \%$ from the initial score in pain intensity or anxiety severity at the final visit) and proportion of patients in remission in terms of anxiety symptoms (HAM-A $<7$ points), or having no pain/mild pain (visual analog scale [VAS] $<4$ points). The effect size (magnitude of changes) was calculated using Cohen's $d$-statistic. ${ }^{31}$ 


\section{Results}

From an initial selection of 90,831 subjects aged over 18 years and assigned to the sites, 2,210 patients, who met the criteria for inclusion in the analysis, were recruited (29 [1.3\%] patients were considered lost to follow-up). In the study group (Figure 1), 1,369 $(61.9 \%)$ received treatment with gabapentin (brand: 400 [29.2\%]; generic: 969 [70.8\%]) and 841 with venlafaxine (brand: 370 [44.0\%]; generic: 471 [56.0\%]). Table 2 shows the demographic characteristics and associated comorbidities for the patients with pNP and GAD. By subgroup (brand, generic), the subjects on treatment with gabapentin had a different proportion of females $(56.3 \%$ vs $63.2 \% ; P=0.017$ ). With venlafaxine, there were no significant differences in any of the descriptive characteristics. There were no statistically significant differences in the distribution of ICPC/ICD-9 codes for pNP in the gabapentin groups between brand or generic $(P=0.969)$ : axial radiculopathies, $56.8 \%$ in the brand group and $55.3 \%$ in the generic group; any type of neuralgias, $22.3 \%$ and $22.7 \%$, respectively; neuropathies, $14.5 \%$ and $15.6 \%$, respectively; and other pNP conditions, $6.5 \%$ and $6.4 \%$, respectively.
Table 3 shows the characteristics of medication use. With gabapentin, mean treatment duration was longer for brand than generic (7.3 vs 6.3 months; $P<0.001$ ); adherence expressed as MPR $(86.5 \%$ vs $81.3 \% ; P<0.001)$ and mean daily dose of medication $(1,322.5$ vs $1,153.5 \mathrm{mg} ; P=0.008)$ were higher; and treatment persistence was significantly longer (Figure $2 \mathrm{~A}$ ). With venlafaxine, mean treatment duration ( 8.8 vs 8.1 months; $P=0.002)$, MPR $(82.1 \%$ vs $79.0 \% ; P=0.045)$, and treatment persistence time (Figure 2B) were all slightly longer with brand than with generic drug, but statistically significant. The medication prescribed to the patients in the pre-treatment (6 previous months) and treatment (12-month follow-up) periods are shown in Table 4. In the gabapentin group, the average number of concomitant medications administered to patients before receiving the initial brand medication (pre-treatment vs treatment period) decreased significantly in the case of brand (2.3 vs 1.9 drugs; $P<0.001$ ), whereas there was no reduction in the case of generic ( 2.6 vs 2.5 drugs; $P=0.261$ ), meaning that during the study, patients taking brand gabapentin used fewer drugs concomitantly for the neuropathic pain ( $1.9 \mathrm{vs} 2.5$; $P<0.001$ ) (Table 4). In the venlafaxine group, the average

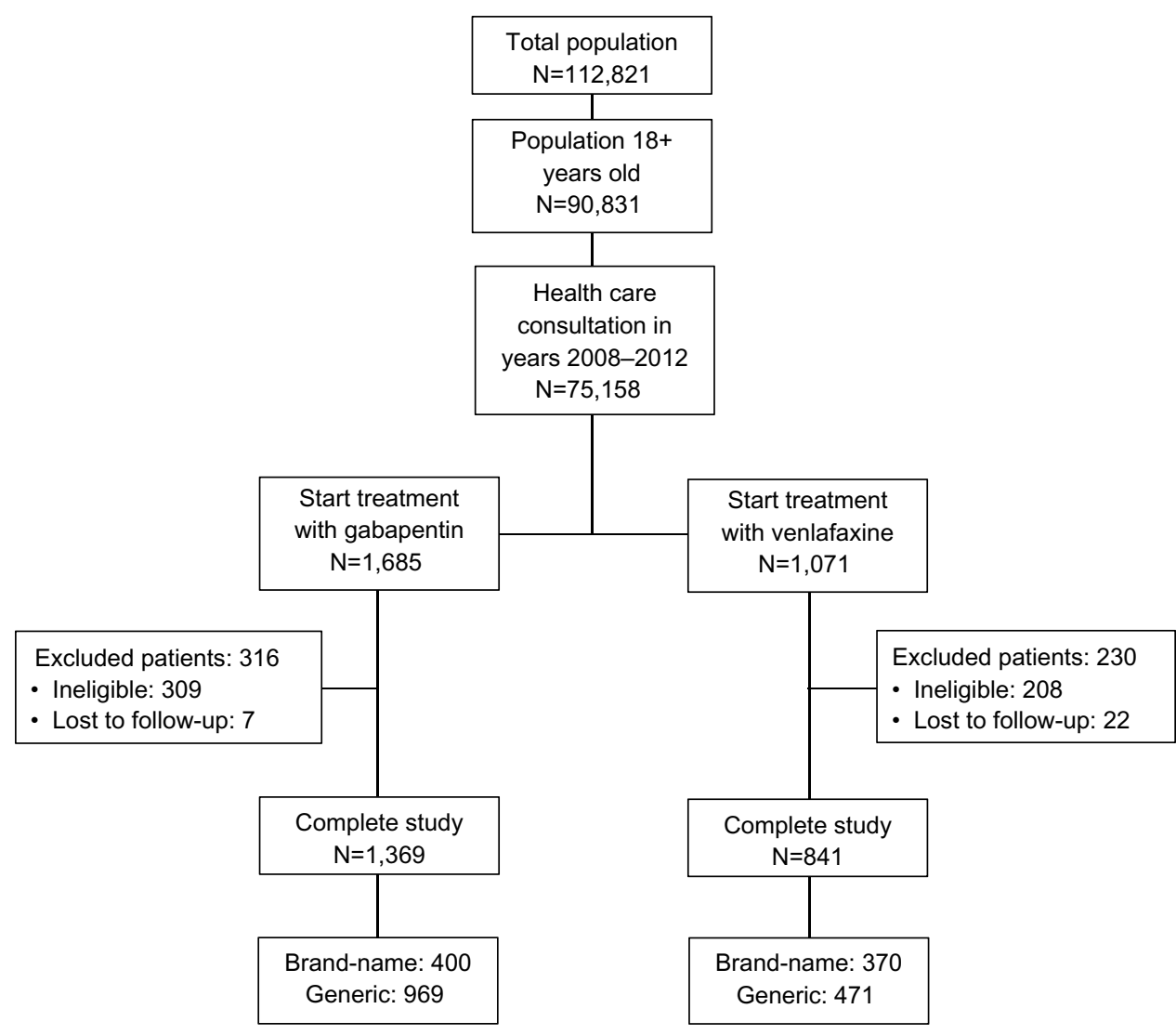

Figure I General outline of the study.

Note: An observational retrospective design involving the review of existing medical records (computerized databases with existing data dissociated) of patients under primary care and hospital follow-up who started treatment with gabapentin or venlafaxine (brand-name vs generic). 
Table 2 Baseline characteristics of study series

\begin{tabular}{|c|c|c|c|c|c|c|c|c|}
\hline \multirow{2}{*}{$\begin{array}{l}\text { Study groups } \\
\text { Subgroups }\end{array}$} & \multicolumn{4}{|c|}{ Gabapentin } & \multicolumn{4}{|c|}{ Venlafaxine } \\
\hline & \multirow{3}{*}{$\begin{array}{l}\text { Brand } \\
\mathrm{N}=400 \\
(29.2 \%)\end{array}$} & \multirow{3}{*}{$\begin{array}{l}\text { Generic } \\
\mathbf{N}=969 \\
(70.8 \%)\end{array}$} & \multirow{3}{*}{$\begin{array}{l}\text { Total } \\
\mathrm{N}=1,369 \\
(100 \%)\end{array}$} & \multirow[t]{3}{*}{$P$} & \multirow{3}{*}{$\begin{array}{l}\text { Brand } \\
\mathrm{N}=370 \\
(44.0 \%)\end{array}$} & \multirow{3}{*}{$\begin{array}{l}\text { Generic } \\
\mathrm{N}=47 \mathrm{I} \\
(56.0 \%)\end{array}$} & \multirow{3}{*}{$\begin{array}{l}\text { Total } \\
\mathrm{N}=84 \mathrm{I} \\
(\mathrm{I} 00 \%)\end{array}$} & \multirow[t]{3}{*}{$P$} \\
\hline Number of patients, $\%$ & & & & & & & & \\
\hline & & & & & & & & \\
\hline \multicolumn{9}{|l|}{ Demographic characteristics } \\
\hline Average age, years & $64.2(16.4)$ & $64.8(15.6)$ & $64.6(15.9)$ & 0.525 & $61.0(17.1)$ & $60.5(16.9)$ & $60.7(17.0)$ & 0.656 \\
\hline Sex (female) & $56.3 \%$ & $63.2 \%$ & $61.1 \%$ & 0.017 & $61.4 \%$ & $66.7 \%$ & $64.3 \%$ & 0.110 \\
\hline Pension regime, SS & $67.5 \%$ & $66.4 \%$ & $66.7 \%$ & 0.683 & $57.3 \%$ & $55.8 \%$ & $56.5 \%$ & 0.672 \\
\hline Range: 19-44 years & $13.8 \%$ & $11.9 \%$ & $12.4 \%$ & & $18.1 \%$ & $19.7 \%$ & $19.0 \%$ & \\
\hline 45-64 years & $33.0 \%$ & $36.1 \%$ & $35.2 \%$ & & $38.9 \%$ & $38.4 \%$ & $38.6 \%$ & \\
\hline $65-74$ years & $22.8 \%$ & $19.5 \%$ & $20.5 \%$ & & $17.3 \%$ & $16.6 \%$ & $16.9 \%$ & \\
\hline$>74$ years & $30.5 \%$ & $32.5 \%$ & $31.9 \%$ & 0.333 & $25.7 \%$ & $25.3 \%$ & $25.4 \%$ & 0.943 \\
\hline \multicolumn{9}{|l|}{ General comorbidity } \\
\hline Average number of diagnoses & $7.0(3.8)$ & $7.1(3.5)$ & $7.1(3.6)$ & 0.643 & $7.0(3.8)$ & 7.I (4.0) & $7.1(3.9)$ & 0.816 \\
\hline Average Charlson index & $0.7(I . I)$ & $0.7(\mathrm{I} .0)$ & $0.7(1.0)$ & 0.930 & $0.6(0.9)$ & $0.6(0.8)$ & $0.6(0.9)$ & 0.864 \\
\hline Average RUB & $2.9(0.6)$ & $2.9(0.6)$ & $2.9(0.6)$ & 0.777 & $2.9(0.6)$ & $2.9(0.6)$ & $2.9(0.6)$ & 0.527 \\
\hline RUB-I & $3.3 \%$ & $4.4 \%$ & $4.1 \%$ & & $3.2 \%$ & $3.8 \%$ & $3.6 \%$ & \\
\hline RUB-2 & $12.5 \%$ & $10.2 \%$ & $10.9 \%$ & & $13.8 \%$ & $12.3 \%$ & $13.0 \%$ & \\
\hline RUB-3 & $73.5 \%$ & $76.4 \%$ & $75.5 \%$ & & $73.8 \%$ & $73.2 \%$ & $73.5 \%$ & \\
\hline RUB-4 & $10.0 \%$ & $7.4 \%$ & $8.2 \%$ & & $8.9 \%$ & $9.3 \%$ & $9.2 \%$ & \\
\hline RUB-5 & $0.8 \%$ & $1.5 \%$ & $1.3 \%$ & 0.178 & $0.3 \%$ & $1.3 \%$ & $0.8 \%$ & 0.542 \\
\hline \multicolumn{9}{|l|}{ Associated comorbidities } \\
\hline Hypertension & $40.3 \%$ & $44.2 \%$ & $43.0 \%$ & 0.183 & $35.6 \%$ & $37.6 \%$ & $36.7 \%$ & 0.555 \\
\hline Diabetes mellitus & $18.8 \%$ & $21.4 \%$ & $20.6 \%$ & 0.277 & $16.0 \%$ & $15.1 \%$ & $15.5 \%$ & 0.703 \\
\hline Dyslipidemia & $43.5 \%$ & $48.2 \%$ & $41.2 \%$ & 0.172 & $44.0 \%$ & $48.6 \%$ & $46.6 \%$ & 0.185 \\
\hline Obesity & $17.5 \%$ & $20.1 \%$ & $20.5 \%$ & 0.214 & $14.1 \%$ & $17.4 \%$ & $16.0 \%$ & 0.198 \\
\hline Active smokers & $22.0 \%$ & $21.4 \%$ & $21.5 \%$ & 0.794 & $19.3 \%$ & $21.9 \%$ & $20.7 \%$ & 0.361 \\
\hline Alcoholism & $3.5 \%$ & $3.2 \%$ & $3.3 \%$ & 0.776 & $5.7 \%$ & $3.2 \%$ & $4.3 \%$ & 0.074 \\
\hline Ischemic heart disease & $7.3 \%$ & $7.8 \%$ & $7.7 \%$ & 0.708 & $5.7 \%$ & $6.6 \%$ & $6.2 \%$ & 0.602 \\
\hline CVA & $12.5 \%$ & $12.6 \%$ & $12.6 \%$ & 0.963 & $11.4 \%$ & $11.0 \%$ & $11.2 \%$ & 0.865 \\
\hline Cardiovascular event & $17.5 \%$ & $17.9 \%$ & $17.8 \%$ & 0.876 & $14.9 \%$ & $14.9 \%$ & $14.9 \%$ & 0.973 \\
\hline Organ failure & $14.0 \%$ & $16.6 \%$ & $15.9 \%$ & 0.228 & $12.8 \%$ & $12.7 \%$ & $12.8 \%$ & 0.989 \\
\hline Asthma & $6.0 \%$ & $7.2 \%$ & $6.9 \%$ & 0.415 & $6.8 \%$ & $5.2 \%$ & $5.8 \%$ & 0.149 \\
\hline COPD & $6.3 \%$ & $5.8 \%$ & $5.9 \%$ & 0.737 & $3.5 \%$ & $4.7 \%$ & $4.2 \%$ & 0.413 \\
\hline Neuropathies & $2.8 \%$ & $1.3 \%$ & $1.8 \%$ & 0.071 & $2.4 \%$ & $1.3 \%$ & $1.8 \%$ & 0.204 \\
\hline Dementia (all types) & $4.5 \%$ & $2.8 \%$ & $3.3 \%$ & 0.106 & $4.3 \%$ & $5.5 \%$ & $5.0 \%$ & 0.440 \\
\hline Organic psychosis & $1.0 \%$ & $0.7 \%$ & $0.8 \%$ & 0.601 & $4.1 \%$ & $5.5 \%$ & $4.9 \%$ & 0.336 \\
\hline Malignant neoplasms & $15.0 \%$ & $12.2 \%$ & $13.0 \%$ & 0.158 & $7.1 \%$ & $9.6 \%$ & $8.5 \%$ & 0.199 \\
\hline
\end{tabular}

Note: Values are expressed as percentage or mean ( \pm standard deviation).

Abbreviations: SS, social security; RUB, resource utilization bands; CVA, cerebrovascular accident.

number of concomitant medications was also higher in the generic group ( 2.5 vs 2.0 drugs; $P<0.001$ ), with a significant reduction in use of concomitant medication in the case of brand venlafaxine ( -0.25 drugs; $P=0.001)$ which was not observed in the generic group. This was due, particularly, to a reduction in the use of anxiolytics (sedatives/hypnotics; $64.3 \%$ vs $51.6 \%$; $P<0.001)$. Once again, these differences were not found in the generic subgroup ( 2.6 vs 2.5 drugs; $P=0.117$ ); however, a reduction was found in the use of anxiolytics $(74.9 \%$ vs $67.5 \% ; P<0.001$ ), although smaller in magnitude than with brand (Table 5).

The use of health care resources was lower in patients treated with brand gabapentin with, in particular, fewer primary care medical visits ( 12.5 vs $15.5 ; P=0.001)$, hospital emergencies ( 0.4 vs $0.7 ; P<0.001)$, and investigations than those who received generic gabapentin (Table 6). In the venlafaxine group, the main differences in favor of the use of brand over generic were seen in primary care medical visits (11.1 vs $13.9 ; P<0.001)$, hospital emergencies ( 0.4 vs 0.6 ; $P=0.006)$, and laboratory tests ( 0.7 vs $1.0 ; P=0.002)$. There were no significant differences in lost labor productivity (Table 5). With gabapentin, the average/total unit cost was greater with the administration of generic than with brand ( $€ 1,665.60$ vs $€ 1,461.40 ; P=0.048$, Table 6). Similar results were found with venlafaxine ( $€ 1,510.10$ vs $€ 1,308.80$; $P=0.040$ ), respectively. With gabapentin, the average/total 


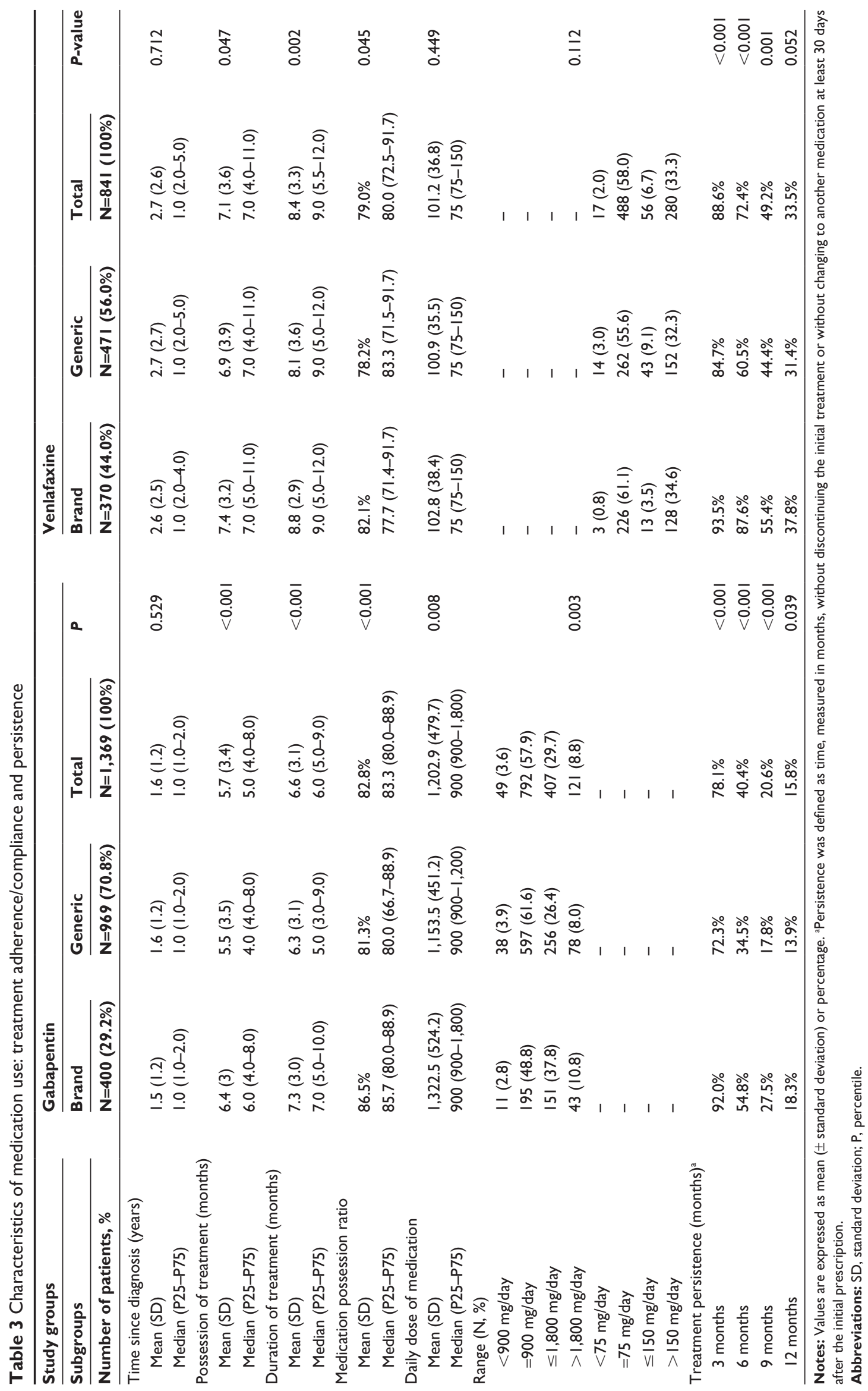



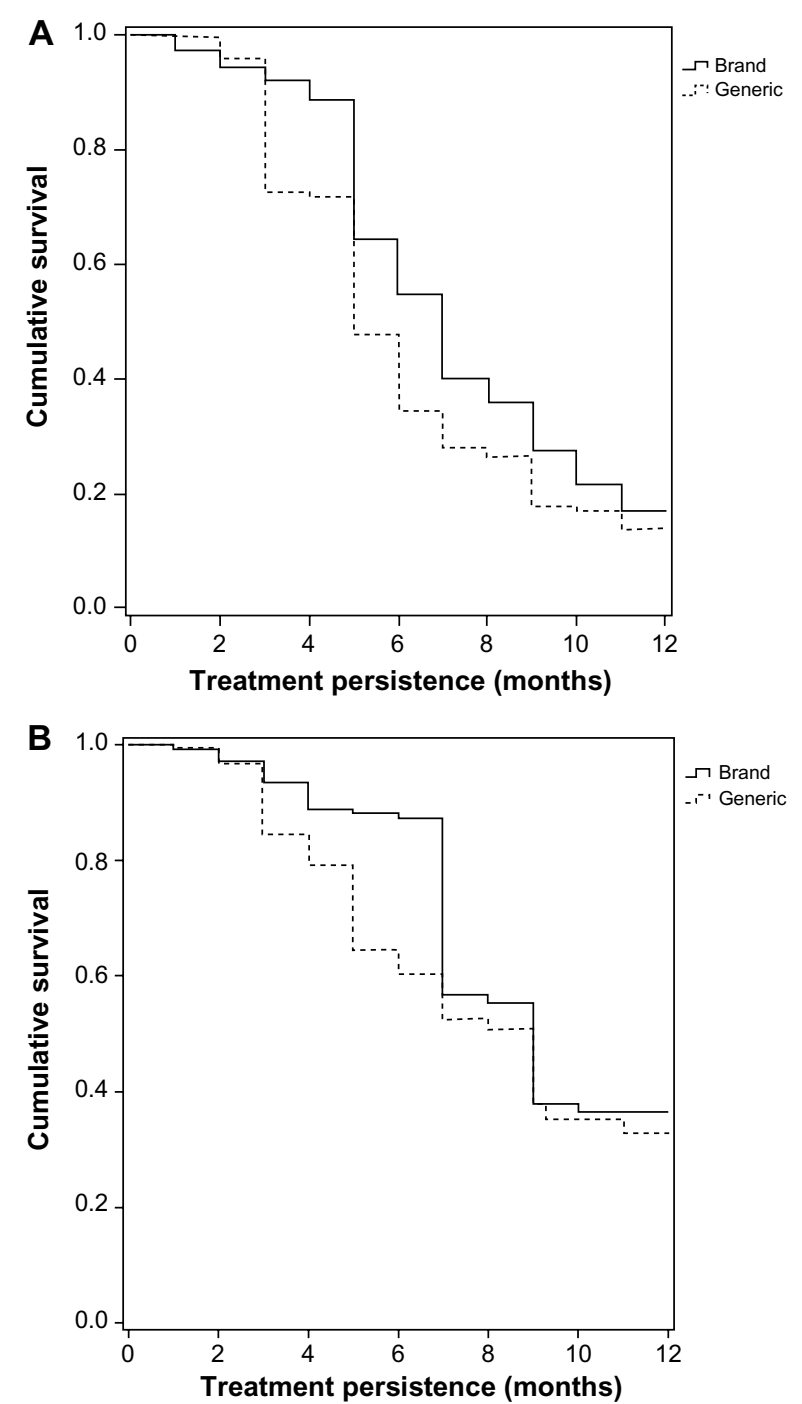

Figure 2 Persistence curve for initial treatment (gabapentin, venlafaxine): comparison of the brand medication with the generic.

Notes: (A) Kaplan-Meier curve for estimation of the median duration of initial treatment with gabapentin. Comparisons between subgroups (brand vs generic): Mantel-Cox log-rank test: 19.54I; $P<0.001$. (B) Kaplan-Meier curve for estimation of the median duration of initial treatment with venlafaxine. Comparisons between subgroups (brand vs generic): Mantel-Cox log-rank test: $6.071 ; P=0.014$.

unit cost adjusted for covariates was $€ 1,720$ versus $€ 1,398$, respectively $(P=0.008)$. The costs incurred in primary care were responsible for a portion of this difference in cost between brand and generic ( $€ 855$ vs $€ 722 ; P<0.001$ ), while the differences observed in specialist care did not reach statistical significance $(P=0.075)$. Again, the results for venlafaxine were similar (Table 6). The average/total unit cost adjusted for covariates was higher with generic ( $€ 1,549$ vs $€ 1,290$; $P=0.035)$; also due to the primary care component (€796 vs $€ 670 ; P=0.001$ ) respectively. Comparing generic with brand, for gabapentin, the adjusted average total health care costs per patient were $€ 1,277$ versus $€ 1,057$ (difference $€ 220, P<0.001)$, and for venlafaxine, $€ 1,110$ versus $€ 928$ (difference $€ 182, P<0.020$ ). In both cases, the higher costs with generic were due to greater use of visits and concomitant medication (Tables 5 and 6).

Although no statistically significant differences were found in scores on the pain and anxiety scales at baseline between groups, patients treated with brand gabapentin showed a greater adjusted relative reduction in pain at the end of the study compared with generic: on average $51 \%$ with brand compared to $43 \%$ with generic $(P<0.001, d=0.36)$, leading to a proportion of responders 3.1 times higher (64\% vs $39 \% ; P<0.001)$ and 2.7 times higher in terms of patients with no pain/mild pain (58\% vs $38 \%, P<0.001)$ (Table 7$)$. Patients on treatment with venlafaxine had similar results in the reduction of anxiety (HAM-A), with an adjusted relative reduction in anxiety symptoms at the end of the study of $62 \%$ on average with brand versus $48 \%$ with generic $(P<0.001$; $d=0.51$ ), leading to a proportion of responders 5.5 times higher $(67 \%$ vs $39 \% ; P<0.001)$, and patients in remission, 10.7 times higher (16\% vs $2 \% ; P<0.001)$ (Table 7$)$.

\section{Discussion}

The two health conditions studied here are relevant and pertinent because of their elevated prevalence at primary care level and burden for medical care. Also, we selected two types of drugs to consistently illustrate the differences between brand-name drugs and generic drugs. The results of the study show that when comparing generic and brand gabapentin and venlafaxine in patients with pNP and GAD, respectively, generic was shown to have lower adherence and a shorter treatment persistence, which was associated with incremental use of resources producing additional health care costs for the Spanish National Health System. This increment might be considered substantial due to the frequency of these health problems in routine medical practice. There is little evidence available evaluating such measurements in a single study, and this makes our work conceptually attractive and gives it a more comprehensive approach than anything published to date. Moreover, these are patients who did not have their medication changed, but took the medication initially prescribed (although the appearance of generic drugs could vary from one manufacturer to another), and this enhances the measure of effect in our study. However, it has to be said that without adequate standardization of methods in terms of patient characteristics, and the number and extent of the variables studied, the results should be interpreted with caution and we must be conservative about the external validity of the results as the study was carried out in a local population setting only. Furthermore, although previously reported in the 
Table 4 Medication prescribed to the patients in pre-treatment (6 previous months) and treatment (I2-month follow-up)

\begin{tabular}{|c|c|c|c|c|c|c|c|}
\hline \multicolumn{2}{|l|}{ Gabapentin } & \multicolumn{2}{|c|}{ Brand } & \multicolumn{2}{|c|}{ Generic } & \multirow[t]{2}{*}{ Difference $^{a}$} & \multirow[t]{2}{*}{$P$-value } \\
\hline Therapeutic class & Period & $\mathbf{N}$ & Mean (SD) or \% & $\mathbf{N}$ & Mean (SD) or $\%$ & & \\
\hline \multirow[t]{4}{*}{ Average number of drugs } & Pre-treatment & 400 & $2.3(1.2)$ & 969 & $2.6(1.3)$ & 0.3 & $<0.001$ \\
\hline & Treatment & 400 & $1.9(1.1)$ & 969 & $2.5(1.4)$ & 0.5 & $<0.001$ \\
\hline & Difference & & -0.34 & & -0.04 & & \\
\hline & $P$-value & & $<0.001$ & & 0.261 & & \\
\hline \multirow[t]{4}{*}{ NSAIDs } & Pre-treatment & 244 & $61.0 \%$ & 703 & $72.5 \%$ & $11.5 \%$ & 0.001 \\
\hline & Treatment & 192 & $48.0 \%$ & 674 & $69.6 \%$ & $21.6 \%$ & $<0.001$ \\
\hline & Difference & & $-13.0 \%$ & & $-3.0 \%$ & & \\
\hline & $P$-value & & $<0.001$ & & 0.085 & & \\
\hline \multirow[t]{4}{*}{ Analgesics (non-narcotic) } & Pre-treatment & 240 & $60.0 \%$ & 674 & $69.6 \%$ & $9.6 \%$ & 0.011 \\
\hline & Treatment & 186 & $46.5 \%$ & 643 & $66.4 \%$ & $19.9 \%$ & $<0.001$ \\
\hline & Difference & & $-13.5 \%$ & & $-3.2 \%$ & & \\
\hline & $P$-value & & $<0.001$ & & 0.076 & & \\
\hline \multirow[t]{4}{*}{ Opiates } & Pre-treatment & 119 & $29.8 \%$ & 309 & $31.9 \%$ & $2.1 \%$ & 0.689 \\
\hline & Treatment & 110 & $27.5 \%$ & 289 & $29.8 \%$ & $2.3 \%$ & 0.695 \\
\hline & Difference & & $-2.3 \%$ & & $-2.1 \%$ & & \\
\hline & $P$-value & & 0.335 & & 0.189 & & \\
\hline \multirow[t]{4}{*}{ Anxiolytics } & Pre-treatment & 166 & $41.5 \%$ & 455 & $47.0 \%$ & $5.5 \%$ & 0.268 \\
\hline & Treatment & 149 & $37.3 \%$ & 448 & $46.2 \%$ & $9.0 \%$ & 0.055 \\
\hline & Difference & & $-4.3 \%$ & & $-0.7 \%$ & & \\
\hline & $P$-value & & 0.056 & & 0.635 & & \\
\hline \multirow[t]{4}{*}{ Antidepressants } & Pre-treatment & 110 & $27.5 \%$ & 285 & $29.4 \%$ & $1.9 \%$ & 0.557 \\
\hline & Treatment & 115 & $28.8 \%$ & 321 & $33.1 \%$ & $4.4 \%$ & 0.429 \\
\hline & Difference & & $1.3 \%$ & & $3.7 \%$ & & \\
\hline & $P$-value & & 0.559 & & 0.005 & & \\
\hline \multicolumn{2}{|l|}{ Venlafaxine } & \multicolumn{2}{|c|}{ Brand } & \multicolumn{2}{|c|}{ Generic } & Difference $^{a}$ & $P$-value \\
\hline Therapeutic class & Period & $\mathbf{N}$ & Mean (SD) or $\%$ & $\mathbf{N}$ & Mean (SD) or \% & & \\
\hline \multirow[t]{4}{*}{ Average number of drugs } & Pre-treatment & 371 & $2.3(1.5)$ & 471 & $2.6(1.6)$ & 0.3 & 0.002 \\
\hline & Treatment & 371 & $2.0(1.4)$ & 471 & $2.5(1.5)$ & 0.4 & $<0.001$ \\
\hline & Difference & & -0.25 & & -0.10 & & \\
\hline & $P$-value & & 0.001 & & 0.117 & & \\
\hline \multirow[t]{4}{*}{ NSAIDs } & Pre-treatment & 168 & $45.4 \%$ & 257 & $54.6 \%$ & $9.2 \%$ & 0.044 \\
\hline & Treatment & 143 & $38.6 \%$ & 259 & $55.0 \%$ & $16.4 \%$ & 0.002 \\
\hline & Difference & & $-6.8 \%$ & & $0.4 \%$ & & \\
\hline & $P$-value & & 0.017 & & 0.870 & & \\
\hline \multirow[t]{4}{*}{ Analgesics (non-narcotic) } & Pre-treatment & 161 & $43.5 \%$ & 216 & $45.9 \%$ & $2.3 \%$ & 0.699 \\
\hline & Treatment & 160 & $43.2 \%$ & 221 & $46.9 \%$ & $3.7 \%$ & 0.607 \\
\hline & Difference & & $-0.3 \%$ & & $1.1 \%$ & & \\
\hline & $P$-value & & 0.924 & & 0.676 & & \\
\hline Opiates & Pre-treatment & 56 & $15.1 \%$ & 74 & $15.7 \%$ & $0.6 \%$ & 0.887 \\
\hline & Treatment & 65 & $17.6 \%$ & 73 & $15.5 \%$ & $-2.1 \%$ & 0.748 \\
\hline & Difference & & $2.4 \%$ & & $-0.2 \%$ & & \\
\hline & $P$-value & & 0.217 & & 0.901 & & \\
\hline Anxiolytics & Pre-treatment & 238 & $64.3 \%$ & 353 & $74.9 \%$ & $10.6 \%$ & 0.009 \\
\hline & Treatment & 191 & $51.6 \%$ & 318 & $67.5 \%$ & $15.9 \%$ & 0.006 \\
\hline & Difference & & $-12.7 \%$ & & $-7.4 \%$ & & \\
\hline & $P$-value & & $<0.001$ & & $<0.001$ & & \\
\hline Antidepressants & Pre-treatment & 56 & $15.1 \%$ & 75 & $15.9 \%$ & $0.8 \%$ & 0.787 \\
\hline & Treatment & 49 & $13.2 \%$ & 70 & $14.9 \%$ & $1.7 \%$ & 0.667 \\
\hline & Difference & & $-1.9 \%$ & & $-1.0 \%$ & & \\
\hline & $P$-value & & 0.734 & & 0.876 & & \\
\hline Antipsychotic agents & Pre-treatment & 54 & $14.6 \%$ & 89 & $18.9 \%$ & $4.3 \%$ & 0.427 \\
\hline & Treatment & 48 & $13.0 \%$ & 88 & $18.7 \%$ & $5.7 \%$ & 0.358 \\
\hline & Difference & & $-1.6 \%$ & & $-0.2 \%$ & & \\
\hline & $P$-value & & 0.343 & & 0.889 & & \\
\hline
\end{tabular}

Notes: aPercentage difference (treatment and pre-treatment; generic vs brand). During the study period, the patients were taking various medications at the same time. Abbreviations: SD, standard deviation; NSAIDs, nonsteroidal anti-inflammatory drugs. 


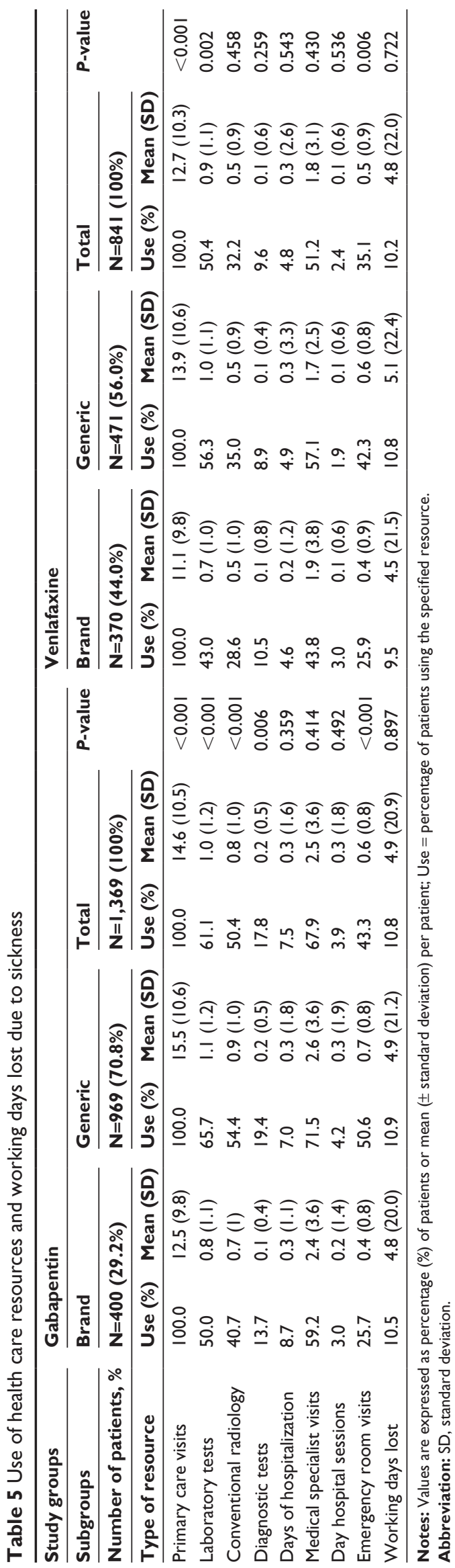

literature, ${ }^{15,33,37,39,40}$ the poorer treatment adherence observed with the generic compared with the brand medications in this study translated into poorer outcomes in the clinical variables, with decreases in pain and symptoms of anxiety significantly larger with the brand than with the generic.

It is known that a generic medicinal product has to have the same qualitative and quantitative composition in active substance and pharmaceutical form and that bioequivalence with the reference medicinal product must have been demonstrated by appropriate bioavailability studies. ${ }^{13,14}$ On the other hand, these drugs have contributed to a reduction in the Health Service's drug bill, leading to the present situation, at least in Spain, where generic and brand medications cost much the same. Therefore, if current regulations are met, there are no pharmacological arguments against the prescribing of these products. ${ }^{32}$ We should also be aware that, in addition to the known reasons for noncompliance or lack of adherence to drug treatment, which may be "intentional" (sociodemographic factors, side effects, drug prices, lack of understanding of treatment or health status, etc) or "unintentional" (forgetting how to take the medication correctly, etc), the study results suggest that administration of a generic drug could be considered an additional factor. ${ }^{33}$

Our results show rates of treatment adherence and persistence significantly higher with brand-name than those of the generic. Although reporting of such data in the literature is not widespread, there are a number of authors who have come to similar conclusions. Håkonsen et $\mathrm{al},{ }^{34}$ for example, found that replacement may be an additional factor in noncompliance and could contribute to confusion among the patients. Kesselheim et al conclude that replacing a brand with a generic should be considered as a factor for noncompliance and higher adverse effect rates. ${ }^{35}$ Ström and Landfeldt showed that replacement of brand alendronate with generic was associated with a reduction in treatment persistence $(66.9 \% \mathrm{vs}$ $51.7 \%$ ), and also conclude that in the design and assessment of health policies, the cost of medications do need to be taken into account, but so do health outcomes..$^{36}$ Our results regarding adherence problems are similar to those described, and we also agree with the opinion of other researchers who believe that, in clinical practice, there may be certain factors concerning the use of generic drugs that could contribute to a lack of adherence and poorer persistence. These include different appearance (colors, shapes) producing potential confusion to the patients (particularly elderly or subjects being treated with polypharmacy), ${ }^{37}$ lack of certain dosage forms (slow release, or absorption), ${ }^{38,39}$ variability in terms of the excipients, ${ }^{40}$ effect of the co-payment, ${ }^{41}$ or even as a 


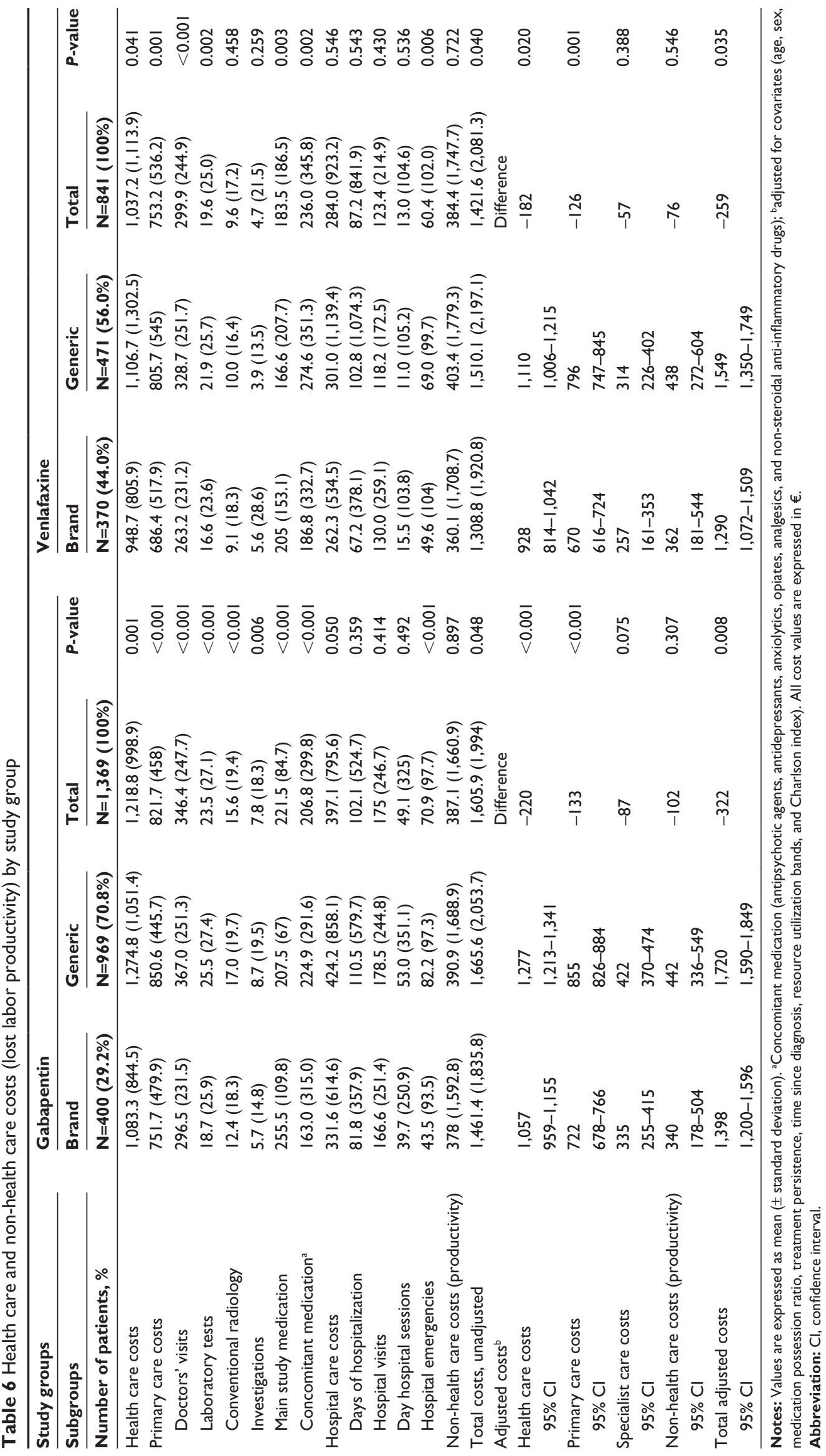


Table 7 Variation of pain intensity and anxiety symptoms between baseline and treatment discontinuation by study group

\begin{tabular}{|c|c|c|c|c|}
\hline Variable & Brand & Generic & Difference/OR $(95 \% \mathrm{CI})^{\mathrm{a}}$ & $P$-value \\
\hline \multicolumn{5}{|l|}{ Pain intensity (VAS) } \\
\hline Start of treatment & $7.1(1.5)$ & $7.2(1.4)$ & $-0.1(-0.1 ; 0.3)$ & 0.340 \\
\hline Treatment discontinuation & $3.6(2.4)$ & $4.1(2.0)$ & $-0.5(-0.7 ;-0.2)$ & $<0.001$ \\
\hline Change start-discontinuation (pts) & $-3.5(2.0)$ & $-3.1(1.8)$ & $-0.5(-0.7 ;-0.2)$ & $<0.001$ \\
\hline Relative variation (\%) & $-51.0(27.5)$ & $-43.2(22.5)$ & $-7.8(-10.7 ;-4.9)$ & $<0.001$ \\
\hline Responders $(\downarrow \geq 50 \%)$, \% & 64.3 & 38.8 & $3.1(2.4 ; 4.1)^{\mathrm{b}}$ & $<0.001$ \\
\hline Remission (<4 pts), \% & 58.3 & 37.6 & $2.7(2.0 ; 3.5)^{b}$ & $<0.001$ \\
\hline \multicolumn{5}{|l|}{ Anxiety symptoms (HAM-A) } \\
\hline Start of treatment & $24.8(6.9)$ & $25.6(6.7)$ & $-0.9(-1.9 ; 0.2)$ & 0.108 \\
\hline Treatment discontinuation & $9.5(2.6)$ & $13.0(5.1)$ & $-3.4(-4.0 ;-2.9)$ & $<0.001$ \\
\hline Change start-discontinuation (pts) & $-15.7(5.7)$ & $-12.3(5.5)$ & $-3.4(-4.0 ;-2.9)$ & $<0.001$ \\
\hline Relative variation (\%) & $-61.5(10.1)$ & $-48.2(13.6)$ & $-13.2(-15.1 ;-11.4)$ & $<0.001$ \\
\hline Responders $(\downarrow \geq 50 \%), \%$ & 67.0 & 39.1 & $5.5(3.8 ; 8.1)^{\mathrm{b}}$ & $<0.001$ \\
\hline Remission (<7 pts), \% & 15.9 & 1.9 & $10.7(5.1 ; 22.8)^{\mathrm{b}}$ & $<0.001$ \\
\hline
\end{tabular}

Notes: Values are expressed as mean ( \pm standard deviation) unless otherwise specified. VAS, range 0-10; HAM-A, range 0-56; ${ }^{2}$ values adjusted for age, sex, and score at start of treatment; ' $\mathrm{OR}$.

Abbreviations: OR, odds ratio; $\mathrm{Cl}$, confidence interval; VAS, visual analog scale; pts, points; HAM-A, Hamilton Anxiety Rating Scale.

result of the nocebo effect, ${ }^{42}$ which might drive the patients to temporarily interrupt the treatment and/or discontinue definitively the therapy until his/her family physician makes a decision.

The results of our study are the first to show that the use of generics is associated with increased use of health care resources and costs, with a degree of clinical effectiveness somewhat inferior to the brand drug in the two drugs analyzed. The temporal relationship between lack of adherence, lower persistence, less clinical effectiveness, and more use of health resources is beyond doubt and very consistent in the literature. ${ }^{33,43,44}$ However, one criticism may be raised by the fact that patients receiving generics were taken more drugs in the pretreatment period both with gabapentin and venlafaxin as well. Consequently, that could jeopardize the baseline comparability of groups since it could be interpreted as certain channeling effect toward including more refractory patients in the generic cohorts. Nevertheless, at least in the case of the gabapentin group, such differences accounted for medicines (nonsteroidal anti-inflammatory drugs [NSAIDs] and non-narcotic analgesics) with a limited use in neuropathic pain conditions making such criticism less plausible. Also, and although not pair-matched because of the sample size, brand-name and generic cohorts were fairly comparable at baseline in all but one variable (sex in the case of the gabapentin group), and the multivariate statistic methodology applied accounted for possible confounders that usually are a source of differential health resource use and costs.

On the other hand, Tran et al report that the use of generics is associated with a reduction in therapeutic control objectives (clinical effectiveness: LDL cholesterol) in the treatment of dyslipidemia and, in a prospective study, ${ }^{45}$ Gagne et al found that patients starting treatment with generic statins, compared with brand, had a higher noncompliance and higher rates of cardiovascular events. ${ }^{19}$ The previously mentioned data cannot be generalized, but are consistent with other published studies. ${ }^{33}$ The results also show that the cost of background drugs was higher in patients treated with brand gabapentin and venlafaxine. This could be due to three factors: 1) the study had a long patient inclusion period ( 5 years), in the early years of which the price of brand drugs was higher than generics (they were not at reference price);2) treatment adherence and persistence among these patients was also higher; and 3) there was a greater proportion of patients (particularly in the gabapentin group) who had received higher doses of the drug. The most plausible explanation, however, may be the greater persistence with brand treatment. The higher cost of drugs mentioned earlier was offset by lower total costs, mainly due to a reduction in medical visits and concomitant medications for the health conditions assessed here. The estimated potential saving per patient/year using brand instead of generic was $€ 322$ with gabapentin and $€ 259$ with venlafaxine ( $€ 220$ and $€ 182$ if health care costs alone are considered, respectively). It is our opinion that this reduction in unit costs (about $17 \%$ with an effect size according to Cohen's $d$-statistic of moderate magnitude) $)^{31}$ is meaningful in terms of efficiency in the clinical management of this group of patients given the high prevalence of these disorders. The influence of the factors discussed earlier (factors associated with lack of adherence with generics) has probably affected all this. ${ }^{37-43}$ 
The results of this study point to some strategies for intervention, especially for policy-makers and health service governing bodies. Changes in the appearance of the drug can cause patients to lose confidence in the safety or effectiveness of the generic prescription, affecting non-adherence to treatment, especially in chronic diseases and patients on multiple medications. ${ }^{17,19,33}$ Reducing the variability in appearance among drugs which are chemically identical could help promote adherence. ${ }^{37}$ Initially, the governing bodies could make it a requirement of new applicants for generics that the shape and color of the pills are homogeneous and consistent with the brand medication. However, the most plausible and practical suggestion would be that having such a demanding policy on the use of generics is no longer necessary, since it has ceased to be an argument for reducing pharmaceutical expenditure.

\section{Limitations}

The possible limitations of the study are those inherent to retrospective studies, such as under-registering of resources use, coding errors of disorders, or possible variability among the health care professionals and patients due to the observational design, or even the costing system used and the possibility of a classification bias. In this regard, any inaccuracy in diagnostic coding in the diagnosis of pNP or GAD, or the lack of some variable that could influence the final results (socioeconomic status of patients, changes in the drug doses prescribed, changes in form and presentation in the generics, etc), should be considered as a limitation of the study. Moreover, we were not able to obtain data for all patients on measurement of clinical effectiveness (health outcomes, assessment scales), especially in the final period; however, this omission was spread evenly between the study's two subgroups and the fact that the imputation was very conservative (worst available value) confers a certain degree of robustness to the results. However, we believe that the main drawbacks of this study, and where the results should be interpreted with caution, are: 1) selection bias by the physician when starting brand or generic treatment, since this was not done randomly as is usual in routine clinical practice which may jeopardize the comparability of groups; and 2) the external validity of the results (generalizability of the data), since the study was conducted in a single local health service-providing organization.

Future prospects offered by this study should focus on replication in other health care institutions and promoting intervention strategies designed to promote adherence to medicines. In conclusion, patients who started treatment with brand-name gabapentin (pNP) and venlafaxine (GAD) showed greater adherence and persistence to treatment and better outcomes in the clinical variables compared with generics, resulting in lower costs for the Spanish National Health System.

\section{Authors' contributions}

All authors contributed toward data analysis, drafting and critically revising the paper and agree to be accountable for all aspects of the work.

\section{Disclosure}

J Rejas-Gutiérrez is an employee of Pfizer SLU. The other authors have no conflicts of interest in this work. No funding was received for this study.

\section{References}

1. Dworkin RH, O'Connor AB, Kent J, et al. International Association for the Study of Pain Neuropathic Pain Special Interest Group. Interventional management of neuropathic pain: NeuPSIG recommendations. Pain. 2013;154:2249-2261.

2. Attal N, Cruccu G, Baron R, et al. European Federation of Neurological Societies. EFNS guidelines on the pharmacological treatment of neuropathic pain: 2010 revision. Eur J Neurol. 2010;17:1113-e1188.

3. BarrettAM, Lucero MA, Le T, Robinson RL, Dworkin RH, Chappell AS Epidemiology, public health burden, and treatment of diabetic peripheral neuropathic pain: a review. Pain Med. 2007;8(Suppl 2): S50-S62.

4. Smith BH, Torrance N. Epidemiology of neuropathic pain and its impact on quality of life. Curr Pain Headache Rep. 2012;16:191-198.

5. Bereza BG, Machado M, Ravindran AV, Einarson TR. Evidencebased review of clinical outcomes of guideline-recommended pharmacotherapies for generalized anxiety disorder. Can J Psychiatry. 2012;57:470-478.

6. Parmentier H, García-Campayo J, Prieto R. Comprehensive review of generalized anxiety disorder in primary care in Europe. Curr Med Res Opin. 2013;29:355-367.

7. Combs H, Markman J. Anxiety Disorders in Primary Care. Med Clin North Am. 2014;98:1007-1023.

8. Weisberg RB. Overview of generalized anxiety disorder: epidemiology, presentation, and course. J Clin Psychiatry. 2009;70(Suppl 2):4-9.

9. Doth AH, Hansson PT, Jensen MP, Taylor RS. The burden of neuropathic pain: a systematic review and meta-analysis of health utilities. Pain. 2010;149:338-344.

10. Hoffman DL, Dukes EM, Wittchen HU. Human and economic burden of generalized anxiety disorder. Depress Anxiety. 2008;25:72-90.

11. Turk DC, Audette J, Levy RM, Mackey SC, Stanos S. Assessment and treatment of psychosocial comorbidities in patients with neuropathic pain. Mayo Clin Proc. 2010;85(Suppl 3):S42-S50.

12. Henning ER, Turk CL, Mennin DS, Fresco DM, Heimberg RG. Impairment and quality of life in individuals with generalized anxiety disorder. Depress Anxiety. 2007;24:342-349.

13. Unterecker S, Proft F, Riederer P, Lauer M, Deckert J, Pfuhlmann B The comparison of brand-name and generic formulations of venlafaxine: a therapeutic drug monitoring analysis. Ther Drug Monit. 2014;36: 269-272.

14. Maly J, Dosedel M, Kubena A, Vlcek J. Analysis of pharmacists' opinions, attitudes and experiences with generic drugs and generic substitution in the Czech Republic. Acta Pol Pharm. 2013;70:923-931. 
15. Corrao G, Soranna D, La Vecchia C, et al. Medication persistence and the use of generic and brand-name blood pressure-lowering agents. J Hypertens. 2014;32:1146-1153; discussion 1153.

16. Chen HY, Chang HR, Lang HC. Effects of hospital generic drug substitution on diabetes therapy. Patient Prefer Adherence. 2014;8: 127-133.

17. Olesen C, Harbig P, Barat I, Damsgaard EM. Generic substitution does not seem to affect adherence negatively in elderly polypharmacy patients. Pharmacoepidemiol Drug Saf. 2013;22:1093-1098.

18. Candido KD, Chiweshe J, Anantamongkol U, Knezevic NN. Can chronic pain patients be adequately treated using generic pain medications to the exclusion of brand-name ones? Am JTher. August 26, 2014. [Epub ahead of print.]

19. Gagne JJ, Choudhry NK, Kesselheim AS, et al. Comparative effectiveness of generic and brand-name statins on patient outcomes: a cohort study. Ann Intern Med. 2014;161:400-407.

20. Sicras-Mainar A, Navarro-Artieda R. Use of metformin and vildagliptin for treatment of type 2 diabetes in the elderly. Drug Des Devel Ther. 2014;8:1-8.

21. Lamberts H, Wood M, Hofmans-Okkes ÍM, editors. The International Classification of Primary Care in the European Community. With a Multi-Language Layer. Oxford: Oxford University Press; 1993.

22. Chaffee A, Yakuboff M, Tanabe T. Responsiveness of the VAS and McGill pain questionnaire in measuring changes in musculoskeletal pain. J Sport Rehabil. 2011;20:250-255.

23. Balon R. Rating scales for anxiety/anxiety disorders. Curr Psychiatry Rep. 2007;9:271-277.

24. Charlson ME, Pompei P, Ales KL, Mackenzie CR. A new method of classifying prognostic comorbidity in longitudinal studies: development and validation. J Chronic Dis. 1987;40:373-383.

25. Weiner JP, Starfield BH, Steinwachs DM, Mumford LM. Development and application of a population-oriented measure of ambulatory care case-mix. Med Care. 1991:29:452-472.

26. WHO. The Anatomical Therapeutic Chemical Classification System. 1991.

27. Steiner JF, Prochazka AV. The assessment of refill compliance using pharmacy records: methods, validity, and applications. J Clin Epidemiol. 1997;50:105-116.

28. Benner JS, Glynn RJ, Mogun H, Neumann PJ, Weinstein MC, Avorn J. Long-term persistence in use of statin therapy in elderly patients. JAMA. 2002;288:455-461.

29. Instituto Nacional de Estadística 2013. 2013 Labour Costs Survey. Available from: http://www.ine.es/dyngs/INEbase/es/operacion.htm? $\mathrm{c}=$ Estadistica_C\&cid $=1254736060920 \&$ menu $=$ ultiDatos\&idp $=1254$ 735976596. Accessed March 1, 2014.

30. Thompson SG, Barber JA. How should cost data in pragmatic randomised trials be analysed? BMJ. 2000;320:1197-1200.
31. Kazis LE, Anderson JJ, Meenan RF. Effect sizes for interpreting changes in health status. Med Care. 1989;27:S178-S189.

32. Puig-Junoy J. Policies for pricing competition in the market of generics: lessons from the European experience. Gac Sanit. 2010;24:193-199. Spanish.

33. Sicras Mainar A, Navarro Artieda R. Influence of substitution of brand name for generic drugs on therapeutic compliance in hypertension and dyslipidemia. Gac Sanit. 2010;24:473-482.

34. Håkonsen H, Eilertsen M, Borge H, Toverud EL. Generic substitution: additional challenge for adherence in hypertensive patients? Curr Med Res Opin. 2009;25:2515-2521.

35. Kesselheim AS, Misono AS, Lee JL, et al. Clinical equivalence of generic and brand-name drugs used in cardiovascular disease: a systematic review and meta-analysis. JAMA. 2008;300:2514-2526.

36. Ström O, Landfeldt E. The association between automatic generic substitution and treatment persistence with oral bisphosphonates. Osteoporos Int. 2012;23:2201-2209.

37. Kesselheim AS, Misono AS, Shrank WH, et al. Variations in pill appearance of antiepileptic drugs and the risk of non-adherence. JAMA Intern Med. 2013;173:202-208.

38. Gasser UE, Fischer A, Timmermans JP, Arnet I. Pharmaceutical quality of seven generic Levodopa/Benserazide products compared with original Madopar ${ }^{\mathbb{R}} /$ Prolopa $^{\circledR}$. BMC Pharmacol Toxicol. 2013;14:24.

39. Sander JW, Ryvlin P, Stefan H, Booth DR, Bauer J. Generic substitution of antiepileptic drugs. Expert Rev Neurother. 2010;10:1887-1898.

40. Narayanaswamy A, Neog A, Baskaran M, et al. A randomized, crossover, open label pilot study to evaluate the efficacy and safety of Xalatan in comparison with generic Latanoprost (Latoprost) in subjects with primary open angle glaucoma or ocular hypertension. Indian J Ophthalmol. 2007;55:127-131

41. Steinman MA, Sands LP, Covinsky KE. Self-restriction of medications due to cost in seniors without prescription coverage. J Gen Intern Med. 2001;16:793-799.

42. Weissenfeld J, Stock S, Lüngen M, Gerber A. The nocebo effect: a reason for patients' non-adherence to generic substitution? Pharmazie. 2010;65:451-456.

43. Markotic F, Cerni Obrdalj E, Zalihic A, et al. Adherence to pharmacological treatment of chronic nonmalignant pain in individuals aged 65 and older. Pain Med. 2013;14:247-256.

44. Taylor S, Abramowitz JS, McKay D. Non-adherence and non-response in the treatment of anxiety disorders. J Anxiety Disord. 2012;26: 583-589.

45. Tran YB, Frial T, Miller PS. Statin's cost-effectiveness: a Canadian analysis of commonly prescribed generic and brand name statins. Can J Clin Pharmacol. 2007;14:e205-e214.
ClinicoEconomics and Outcomes Research

\section{Publish your work in this journal}

ClinicoEconomics \& Outcomes Research is an international, peerreviewed open-access journal focusing on Health Technology Assessment, Pharmacoeconomics and Outcomes Research in the areas of diagnosis, medical devices, and clinical, surgical and pharmacological intervention. The economic impact of health policy and health systems
Dovepress

organization also constitute important areas of coverage. The manuscript management system is completely online and includes a very quick and fair peer-review system, which is all easy to use. Visit http://www.dovepress.com/testimonials.php to read real quotes from published authors. 